\title{
Analisis Transaksi Financial Technology (Fintech) Syariah dalam Perspektif Maqashid Syariah
}

\author{
Rohmatun Nafiah \\ Program Magister Ekonomi Syariah UIN Sunan Kalijaga Yogyakarta \\ Email: rohmatunnafiah17@gmail.com \\ Ahmad Faih \\ Program Magister Ekonomi Syariah UIN Sunan Kalijaga Yogyakarta \\ Email: Afaih377@gmail.com
}

\begin{abstract}
Abstrak:
This research examines whether fintech is in accordance with maqashid sharia or not. This type of research used in this paper is to use literature studies obtained from various sources. This research is descriptive qualitative, which means describing a research subject. In this case is the development of fintech in Indonesia which is seen from the perspective of sharia maqashid. The nature of this research is descriptive. The results obtained show that Islamic fintech has a Islam maqashid foundation and also has a clear legal protection and contained in the law.

[Penelitian ini meneliti apakah fintech sudah sesuai dengan maqashid syariah atau tidak. Jenis penelitian yang digunakan dalam penelitian ini adalah studi literature yang diperoleh dari bernagai sumber. Penelitian ini juga merupakan penelitian deskriptif kualitatif yang berarti mendeskripsikan subyek penelitian. Hasil yang diperoleh menunjukkan bahwa fintech sudah memenuhi maqashid syariah dan juga memiliki perlindungan hukum yang jelas dan terkandung dalam perundang-undangan.]
\end{abstract}

Kata Kunci: Transaksi; Fintech; Maqashid Syariah. 


\section{PENDAHULUAN}

Teknologi digital merupakan terobosan serta inovasi baru dalam seluruh kegiatan ekonomi. Hal tersebut dapat mempengaruhi sektor perdagangan, pertanian, dan secara khusus pada sektor keuangan. Salah satu sektor yang saat ini dikembangkan yaitu Financial Technology atau lebih dikenal dengan istilah Fintech yang menjadi inovasi terbaru masa kini. Teknologi finansial adalah bisnis yang berfokus pada penyedia gagasan jasa finansial yang menggunakan perangkat lunak dan modern. Sekarang ini Fintech mendapatkan perhatian secara global sebagai teknologi yang akan memberdayakan perusahaan untuk bersaing dengan efektif pada abad dua puluh satu saat ini. Pemerintah di dunia saat ini telah memberikan perhatian mengenai tantangan dan merancang kebijakan serta peraturan untuk mendukung perkembangan Fintech. Teknologi keuangan atau Fintech di Indonesia merupakan peluang pasar yang sangat potensial. Geografis yang luas, pertumbuhan kelas menengah yang cukup besar, dan potensi produk keuangan yang relatif kurang baik secara bersama-sama bergabung untuk menciptakan pasar yang tangguh untuk pengembangan Fintech di Indonesia. Dengan 36\% dari populasi yang memiliki rekening bank, Fintech di Indonesia menjanjikan layanan keuangan yang dapat diakses kepada penduduk yang tidak tersentuh perbankan (unbankable). Platfrom Fintech di Indonesia secara umum tumbuh dengan pesat dari tahun 2015 hingga akhir 2017. ${ }^{1}$

Pertumbuhan Fintech berdasarkan data yang terdaftar di OJK sampai bulan Maret 2018 mengalami peningkatan yang baik, sekitar 40 perusahaan Fintech syariah sudah mendapat izin resmi untuk beroperasi dari OJK. Sebagai negara berpenduduk muslim terbesar di dunia, prospek industri fintech syariah di Indonesia tampak sangat baik. Secara keseluruhan, Fintech di Indonesia memiliki potensi besar karena dapat memberikan solusi untuk kebutuhan mendesak yang tidak mampu disediakan oleh lembaga keuangan tradisional. Selain itu, ledakan dalam penetrasi seluler $(70 \%$ penduduk menggunakan ponsel untuk mengakses web) di negara ini telah mencapai lahan subur bagi peningkatan pesat industri Fintech.

Berdasarkan data Otoritas Jasa Keuangan (OJK), perusahaan Fintech di Indonesia terbagi kepada beberapa sektor, yaitu: 1) financial planning, 2) lending, 3) crowdfunding, 4) aggregator, 5) payment, dan 6) fintech lainnya. Menurut Hadad menerangkan bahwa perusahaan Fintech di Indonesia didominasi oleh sektor pembayaran (payment) sebesar 42,22\%, sektor pinjaman (lending) 17,78\%, sektor agregator sebesar 12,59\%, sektor perencanaan keuangan (financial planning) sebesar 8,15\%, sektor crowdfunding sebesar $8,15 \%$, dan sektor fintech lainnya sebesar $11,11 \% .^{2}$

Seiring perkembangan Fintech saat ini, maka kesesuaiannya dalam fikih muamalah harus berdasarkan prinsip-prinsip syariah yakni terhindar dari Maysir, Gharar dan Riba. Meskipun kegiatan tersebut menggunakan sistem teknologi maka prinsip-prinsip hukum Islam harus tetap dijalankan. Maka dari itu penelitian terhadap akad tijarah dalam transaksi Fintech dengan pendekatan maqashid syariah ini harus dilakukan sehingga umat muslim dapat mengikuti arus perkembangan teknologi dan lembaga keuangan Fintech sesuai dengan koridor maqashid syariah.

Pendekatan yang dilakukan dalam analisis ini menggunakan pendekatan maqashid syariah sebagai pondasi utama dalam menentukan ijtihad hukum. Agar dapat menciptakan kolerasi antara praktik dengan teori berdasarkan sumber yang berkaitan dengan tema penelitian ini.

\footnotetext{
${ }^{1}$ Hasan S.M, Fintech in Indonesia: An Islamic Outlook. 2018. http://ethiscrowd.com diakses tanggal 15 Juli 2019.

2 Hadad. Financial Technology (Fintech) di Indonesia. (Kuliah Umum Tentang Indonesia Banking School, 2018).
} 


\section{METODE PENELITIAN}

Jenis penelitian yang digunakan dalam tulisan ini adalah dengan menggunakan studi pustaka yang diperoleh dari berbagai sumber. Penelitian ini bersifat deskriptif kualitatif yang artinya menggambarkan suatu subyek penelitian. Dalam hal ini adalah perkembangan Fintech di Indonesia yang mana dilihat dari sudut pandang maqashid syariah. Sifat dari penelitian ini adalah deskriptif, maksudnya untuk mendeskripsikan dan menginterpretasikan hasil temuan atau pengamatan mengenai Fintech yang kian marak perkembangannya di Indonesia saat ini melalui kaca mata maqashid syariah agar dapat diliat relevansinya terhadap koridor syariat Islam.

Jenis data yang digunakan dalam tulisan ini adalah data sekunder, maksudnya adalah data yang diambil peneliti sebagai pendukung atas penelitian secara ilmiah yaitu dengan melakukan studi pustaka (penelusuran melalui buku, artikel, jurnal, majalah, internet dan sumber lainnya). ${ }^{3}$ Teknik pengumpulan data yang diperlukan dalam tulisan ini adalah dengan menggunakan beberapa metode yaitu: studi kepustakaan, metode ini digunakan untuk menggali dasar dasar teori yang terkait dengan konsep dan mekanisme Fintech yang pesat pada saat ini agar tidak kontradiktif dengan prinsip-prinsip syariat Islam. Serta mengetahui perkembangan Fintech saat ini dengan menggunakan maqashid syariah sebagai landasan utama, sehingga dapat menciptakan kolerasi antara praktik dengan teori berdasarkan sumber-sumber ajaran ekonomi Islam.

Penelitian kualitatif adalah prosedur penelitian yang menghasilkan data deskriptif berupa kata-kata tertulis atau lisan dari orang-orang dan keadaan yang diamati. Penelitian kualitatif adalah metode penelitian yang digunakan untuk meneliti pada kondisi objek yang alamiah, (sebagai lawannya adalah eksperimen) dimana peneliti adalah sebagai instrumen kunci, teknik pengumpulan data dilakukan secara trianggulasi (gabungan), analisa data bersifat induktif dan hasil dari penelitian kualitatif lebih bersifat makna dari pada generalisasi. ${ }^{4}$

\section{HASIL DAN PEMBAHASAN}

\section{Sekilas tentang Fintech Secara Umum dan Syariah}

Financial Technology (Fintech) adalah hibridasi teknologi pada proses layanan keuangan tradisional dengan berbasis teknologi. ${ }^{5}$ Menurut PWC pengertian finansial teknologi adalah segmen dinamis di persimpangan antara sektor jasa keuangan dengan teknologi dimana start-up yang berfokus pada teknologi dan merupakan pandangan pasar baru berinovasi produk dan layanan yang saat ini disediakan oleh industri jasa keuangan tradisional. Adapun pengertian lainnya adalah Fintech mengacu pada penggunaan teknologi untuk memberikan solusi dalam sektor keuangan. ${ }^{6}$

Pengertian Fintech Syariah adalah kombinasi, inovasi yang ada dalam bidang keuangan dan teknologi yang memudahkan proses transaksi dan investasi berdasarkan nilainilai syariah. Walaupun Fintech ini merupakan terobosan baru tetapi mengalami perkembangan yang pesat. Islam merupakan agama yang komperhensif sehingga dalam bidang keuangan ini harus memiliki aturan yang sesuai dengan prinsip syariat Islam. ${ }^{7}$

\footnotetext{
3 Farizal. Pengembangan Kompetensi SDM Perbankan Syariah Melalui Corporate University, forum Riset Perbankan Syariah II. Yogyakarta. 2010.

${ }^{4}$ Ibid.

5 Subarjo Joyosumarto. B.A.N.K.I.R. Kepemimpinan Lembaga Perbankan Abad ke-21. Jakarta: PT. Elex Media Komputindo, 2018.

${ }^{6}$ Arner D. W. Opportunities and Challenges. Fintech and RegTech, 2016.

7 https://amartha.com, diakses tanggal 18 Juli 2019.
} 


\section{Perkembangan Fintech Syariah}

Perkembangan teknologi ditandai dengan kemunculan Financial Technology (Fintech) serta menjadi salah satu bukti perkembangan teknologi berbasis digital dimana merupakan inovasi baru dan berdampak pada semua kegiatan ekonomi. Adapun Fintech adalah bisnis yang berfokus pada penyediaan layanan keuangan dengan menggunakan software dan teknologi modern. Selain itu, teori yang menjelaskan tentang Fintech yang diperkenalkan oleh ahli ekonomi Joseph Schumpeter dengan teorinya yaitu creatif destruction yang mana teori ini berisi tentang pernyataan bahwa dengan adanya temuan-temuan baru yang berdampak menghancurkan pemain lama kemudian menggantikannya dengan sesuatu yang baru. Akan tetapi teori ini tidak dapat menjelaskan secara rinci mengenai dampak dari adanya terobosan baru berupa Fintech. Alasannya adalah karena kemunculan Fintech bukan untuk menghancurkan incumbents yang sudah lama keberadaannya. Akan tetapi, Fintech mengurangi secara perlahan fungsi-fungsi incumbents dengan sesuatu yang lebih baik, lebih efektif dan efisien. ${ }^{8}$ Selain itu, tujuan dari adanya Fintech harus selaras dengan tujuan dari transaksinya untuk mendatangkan dan memelihara kemaslahatan (kebaikan) sekaligus menghidari kemafsadatan (kerusakan) baik di dunia maupun di akhirat. ${ }^{9}$

Menyadari besarnya potensi pangsa pasar muslim di dunia, startup Fintech tidak menyia-nyiakan kesempatan dengan membangun Fintech syariah. Fintech syariah memiliki kriteria khusus diantaranya tidak mengandung unsur riba, ghoror (penipuan), madlorot (efek negatif), dan jahalah (tidak ada transparansi) antara penjual dan pembeli. Diawali oleh startup Fintech syariah pertama Beehive di Dubai pada tahun 2004. Fintech yang mendapatkan sertifikat syariah pertama kali di dunia ini menyediakan pembiayaan murah untuk UMKM yang menggunakan pendekatan peer to peer lending marketplace. Di Asia Tenggara, di tahun 2016 Fintech asal singapura, Kapital Boost, telah mendapatkan sertifikat kepatuhan syariah dari Financial Shariah Advisory Consultancy (FSAC) Singapura dan dinamakan sebagai "The First Islamic SME Crowdfunding Platfrom". Juga terdapat Fintech Ethis Crowd dari Singapura yang menguasai pasar Indonesia sejak tahun 2014 dan kini sudah mempunyai layanan syariah. Dalam beberapa tahun terakhir crowdfunding syariah terus berkembang di berbagai belahan dunia diantaranya Alamisharia.com, Indves.com, Blossom, Launch Good, Narwi dan Skola Fund. Di Indonesia sendiri Fintech syariah yang ada saat ini seperti Investree, Start Zakat dan Indves, SyarQ, Mari Usaha (P2P) dan lain-lainnya. Fintech syariah pertama yang mendapatkan sertifikasi halal MUI di Indonesia adalah Paytren di tahun 2017. Meskipun Fintech syariah mulai berkembang tetapi jumlah Fintech konvensional masih jauh lebih banyak dibandingkan dengan Fintech syariah.10

Teknologi finansial saat ini masih didominasi oleh teknologi finansial konvensional, menurut data yang dipublikasikan dalam situs resmi OJK per Juni 2019 terdapat 113 perusahaan penyelenggara layanan teknologi finansial yang mendapatkan izin 0JK, yang mana lebih dari setengah bagiannya adalah layanan berbasis konvensional. ${ }^{11}$ Layanan teknologi finansial tersebut perlahan- lahan masuk ke sistem keuangan syariah.12 Hal ini dibuktikan dengan bermunculannya start-up yang menjalankan bisnisnya berdasarkan prinsip syariah dan sudah terdaftar di OJK dan DSN-MUI, dengan begitu tentu sangat penting

\footnotetext{
8 Kasali. R. Discruption. Jakarta: Gramedia Pustaka Utama, 2017.

9 Shidik. Ushul Fiqh. Jakarta: PT. Intimedia Cipta Nusantara, 2016.

10 Dewi Sartika Nasution. Urgensi Fintech Dalam Kurikulum Pendidikan Tinggi. Iqtishaduna Jurnal Ekonomi Syariah Vol. 8 No.2 Juni 2017.

11 https://www.ojk.go.id/id/berita-dan-kegiatan/publikasi/Pages/Penyelenggara-Fintech-Terdaftar-dan-Berizin, (diakses tanggal 1 Agustus 2019).

12 Didukung dan dikeluarkannya Fatwa Dewan Syariah Nasional- Majelis Ulama Indonesia (DSN-MUI) No. 117/DSN-MUI/II/2018 Tentang Layanan Pembiayaan Berbasis Teknologi Informasi Berdasarkan Prinsip Syariah.
} 
bagi para start-up yang mejalankan sistem bisnis berdasarkan syariah untuk menerapkan ketentuan-ketentuan syariah, mulai dari produk yang ditawarkan, akad yang digunakan sampai rukun dan serta batasan hukumnya sesuai ketentuan fatwa dan tidak bertentangan pula dengan prinsip perlindungan konsumen. ${ }^{13}$

Majelis Ulama Indonesia (MUI) menjawab kegundahan masyarakat tentang produk syariah yang ditawarkan oleh start-up syariah di Indonesia dengan menimbang berbagai aspek, selain memang bisnis teknologi finansial sedang berkembang di Indonesia. Juga dirasa perlu adanya kejelasan mengenai ketentuan dan batasan hukum terkait layanan pembiayaan berbasis teknologi informasi berdasarkan prinsip syariah. MUI mengeluarkan Fatwa Dewan Syariah Nasional-Majelis Ulama Indonesia (DSN-MUI) No. 117/DSN-MUI/II/2018 Tentang Layanan Pembiayaan Berbasis Teknologi Informasi Berdasarkan Prinsip Syariah yang terdiri atas delapan bagian: 1) ketentuan umum; 2) ketentuan hukum; 3) subjek hukum; 4) ketentuan terkait pedoman umum layanan pembiayaan berbasis teknologi informasi; 5) model layanan pembiayaan berbasis teknologi informasi; 6) ketentuan terkait mekanisme dan akad; 7) penyelesaian perselisihan; 8) ketentuan penutup. ${ }^{14}$

Fatwa tersebut menjawab keraguan para konsumen atau pengguna transaksi bisnis teknologi finansial dalam memahami ketentuan dan batasan hukum yang menjadi landasan kesyariahan dari produk yang ditawarkan oleh start-up di Indonesia. Dengan demikian dapat dikatakan pula bahwa fatwa tersebut memberikan kepastian hukum sehingga meningkatkan rasa kepercayaan masyarkat terhadap layanan pembiayaan berdasarkan prinsip syariah yang ditawarkan oleh start-up teknologi fianansial syariah sehingga meningkatkan minat masyarkat untuk melakukan transaksi menggunakan teknologi finansial. ${ }^{15}$

\section{Fintech dan Hubungannya dengan Maqashid Syariah}

Transaksi yang sesuai dengan syariat Islam tentunya yang berlandaskan kepada alQuran dan Hadis. Segala bentuk perekonomian dan transaksi bisnis menurut ajaran Islam yang bersumber dari al-Quran dan Sunnah adalah untuk memperhatikan hak individu yang harus terlindungi sekaligus untuk menegakkan rasa solidaritas yang tinggi terhadap masyarakat. ${ }^{16}$ Pada dasarnya akad yang terdapat dalam Fintech tidak bertentangan selagi tidak bertentangan dengan prinsip syariah. Selain itu, Fintech merujuk kepada salah satu asas muamalah yaitu an-taradhin yang memiliki arti saling ridho diantara kedua belah pihak. Atas dasar inilah akad atau transaksi yang terjadi diantara kedua belah pihak menjadi sah. ${ }^{17}$

Berbeda dengan lembaga keuangan konvensional, lembaga keuangan syariah harus mendasari operasionalnya dengan prinsip syariah yakni larangan atas riba, gharar dan maysir sehingga lebih menekankan kepada sistem bagi hasil (profit and lose sharing) sebagai penggantinya. Para pakar muslim sudah banyak yang menjelaskan bahwa landasan bunga (interest) sangat dilarang karena dapat menimbulkan terjadinya ketidakadilan (injustice) dalam tatanan ekonomi masyarakat. Sebaliknya, lembaga ekonomi syariah secara konsepsional didasarkan atas prinsip kemitraan berdasarkan kesetaraan (equity), keadilan

\footnotetext{
13 Ismiyatul Arifiyah. Perlindungan Hukum Terhadap Pengguna Pada Transaksi Bisnis Teknologi Finansial Berdasarkan Prinsip Syariah. Skripsi Fakultas Ekonomi dan Bisnis UIN Syarif Hidayatullah Jakarta. 2018.

14 Fatwa Dewan Syariah Nasional-Majelis Ulama Indonesia (DSN-MUI) No. 117/DSN-MUI/II/2018 Tentang Layanan Pembiayaan Berbasis Teknologi Informasi Berdasarkan Prinsip Syariah.

15 Ismiyatul Arifiyah. Perlindungan Hukum Terhadap Pengguna Pada Transaksi Bisnis Teknologi Finansial Berdasarkan Prinsip Syariah. Skripsi Fakultas Ekonomi dan Bisnis UIN Syarif Hidayatullah Jakarta. 2018.

${ }^{16}$ Abdul Karim. Hukum Bisnis Syariah dalam Al-Quran. (Jakarta: AMZAH, 2013).

17 Arner. Opportunities and Challenges. Fintech and Reg Tech, 2016.
} 
(fairness), kejujuran (transparan), dan hanya mencari keuntungan yang halal semata (falah oriented). ${ }^{18}$

Kenyamanan yang diberikan atas transaksi melalui Fintech berbasis syariah tidak lepas dari karakteristik bisnis syariah yang bersandar kepada pondasi ekonomi syariah yaitu ketuhanan (ilahiah), keadilan (al-adl), kenabian (an-nubuwwah), pemerintahan (al-khilafah), dan hasil (ma'ad).19 Permintaan pengguna jasa layanan Fintech berbasis syariah yang meningkat yang didukung dengan pangsa pasar pengguna layanan dari masyarakat Indonesia yang mayoritas muslim mendorong layanan Fintech berbasis syariah wajib memenuhi kaidah-kaidah dalam transaksi bisnis secara syariah dan tentunya harus sesuai dengan maqashid syariahnya pula. ${ }^{20}$

Perlu digaris bawahi bahwa layanan Fintech baik yang konvensional maupun syariah haruslah mengedepankan kepentingan pengguna transaksi Fintech. Oleh sebab itu para startup, khusunya yang berprinsip syariah juga harus memuat ketentuan-ketentuan berkenaan dengan perlindungan konsumen yang sudah dimuat dalam POJK No. 77/POJK.01/2016 dan Undang-Undang terkait, yaitu Undang-Undang Nomer 8 Tahun 1999 tentang Perlindungan Konsumen (UUPK), Peraturan Pemerintah Nomer 82 Tahun 2012 Tentang Penyelenggara Sistem dan Transaksi Elektronik (PP PSTE), yang merupakan turunan dari Undang-Undang Nomer 11 Tahun 2008 tentang Informasi dan Transaksi Elektronik (UU ITE). Yang mana isi dari peraturan maupun undang-undangnya ketika ditelaah lebih dalam memeliki relevansi dan kolerasi dengan maqashid syariah, yang tujuannya untuk menjaga kemaslahatan umat manusia, di antaranya: pertama, perlindungan konsumen pada transaksi Fintech sebelum terjadinya akad, yang mencakup; 1) Pendekatan atau edukasi konsumen; 2) Kelengkapan informasi dan transparansi produk layanan; 3) Penanganan pengaduan dan penyelesaian sengketa konsumen; 4) Pencegahan penipuan dan keandalan sistem layanan; dan 5) Perlindungan terhadap data pribadi.

Kedua, perlindungan konsumen pada Fintech sesudah terjadinya akad, yang meliputi; 1) Perlindungan atas penundaan pembayaran; 2) Perlindungan konsumen atas cidera janji; 3) Perlindungan atas penyelesaian sengketa yang patut; dan 4) Analisis kode etik penagihan. ${ }^{21}$

Dalam pelayanan serta fungsi-fungsinya, fintech syariah disesuaikan dengan tujuantujuan dan landasan maqasyid syariah agar dalam praktinya tidak menyimpang dari ajaran agama Islam. Berikut adalah uraian fintech syariah dilihat dari segi maqasyid syariah:

Pertama, Menjaga Agama (Al-Din) mashlahah ini berkaitan dengan kadar keimanan seseorang kepada sang pencipta yaitu Allah SWT yang kemudian diwujudkan dalam bentuk ibadah seperti shalat lima waktu, puasa, zakat, haji dan menunaikan hutang. Dalam hal ini fintech syariah diciptakan dengan maksud memudahkan dalam bertransaksi untuk mencapai kenikmatan ibadah. Dilihat dari jenis-jenisnya salah satu jenis fintech yang mendukung mashlahah ini adalah jenis fintech digital payment dimana didalamnya terdapat fitur yang memungkinkan masyarakat untuk membayar infaq, shodaqah, zakat bahkan menyicil biaya haji. Hal tersebut merupakan salah satu upaya yang dilakukan fintech syariah guna menjaga agama penggunanya.

\footnotetext{
18 Ibid.

19 Fadlan Fadlan, "KONSEP PEMBANGUNAN EKONOMI BERBASIS ISLAM (Sebuah Upaya Pembangunan Ekonomi Indonesia yang Adil, Makmur, dan Sejahtera)," Al-Ihkam: Jurnal Hukum \& Pranata Sosial 5, no. 2 (2012): 257-274. ${ }^{20}$ Achmad Basori Alwi. Pembiayaan Berbasis Teknologi Informasi (Fintech) yang berdasarkan Syariah. Jurnal AlQonun Vol. 21 No.2 Desember 2018.

21 Ismiyatul Arifiyah. Perlindungan Hukum Terhadap Pengguna Pada Transaksi Bisnis Teknologi Finansial Berdasarkan Prinsip Syariah. Skripsi Fakultas Ekonomi dan Bisnis UIN Syarif Hidayatullah Jakarta. 2018.
} 
Kedua, Menjaga Jiwa (Al-Nafs) mashlahah ini berkaitan dengan menjaga kesehatan jiwa seseorang dengan tidak menimbulkan penyakit baik fisik maupun psikis yang dapat mengganggu kesejahteraan. Dari awal pembentukannya fintech syariah mengutamakan mashlahat dimana hal tersebut dimaksudkan agar masyarakat mencapai kesejahteraan dan kemakmuran. Fintech syariah juga dilindungi payung hukum guna memberikan kenyaman bagi penggunanya. Undang-undang tersebut tertuang dalam Undang-Undang Nomer 8 Tahun 1999 tentang Perlindungan Konsumen (UUPK), Peraturan Pemerintah Nomer 82 Tahun 2012 Tentang Penyelenggara Sistem dan Transaksi Elektronik (PP PSTE).

Ketiga, Menjaga Keturunan (Nasb) mashlahah ini berkaitan dengan pernikahan yang menjadi jalan syariah dalam memperoleh keturunan. Fintech syariah sendiri berusaha menjaga keturunan dengan adanya fintech yang berbasis investasi (financing and investment). Dengan adanya fintech syariah jenis ini diharapkan penggunanya dapt memanfaatkannya dengan baik guna merencanakan masa depan keluarga agar tercapai kemakmuran dan keharmonisan dalam keluarga.

Keempat, Menjaga Akal (Al-Aql) mashlahah ini berkaitan dengan ilmu sebagai landasan beragama dan dalam melakukan pekerjaan. Seseorang yang tidak memiliki ilmu tidak akan dapat berfikir mengenai keutamaan-keutamaan dalam beramal. Oleh sebabnya segala sesuatu hendaknya didasari dengan ilmu. Peluncuran Fintech syariah telah dikaji dengan berbagai disiplin ilmu dan kemudian dilandasi dengan undang-undang. Yang mana isi dari peraturan maupun undang-undangnya ketika ditelaah lebih dalam memeliki relevansi dan kolerasi dengan tuntunan maqashid syariah yang ada lima yang mana garis besarnya adalah keterjagaan bagi manusia.

Kelima, Menjaga Harta (Al-Mal) harta merupakan satu komponen penting dalam kehidupan namun bukanlah komponen yang utama. Harta adalah satu alat yang digunakan untuk memenuhi kebutuhan. Harta dapat diperoleh dari perdagangan, kerjasama antar individu dan lain-lain. Dalam Islam sendiri pemerolehan harta harus terbebas dari unsur riba, maysir dan gharar. Selain itu, tujuan dari adanya Fintech harus selaras dengan tujuan dari transaksinya untuk mendatangkan dan memelihara kemaslahatan (kebaikan) sekaligus menghidari kemafsadatan (kerusakan) baik di dunia maupun di akhirat. ${ }^{22}$ Fintech syariah sendiri memiliki kriteria khusus diantaranya tidak mengandung unsur riba, ghoror (penipuan), madlorot (efek negatif) hal itu dimaksudkan agar harta dari pengguna fintech terjaga keamanan dan kehalalanya.

Dengan demikian, bisa dilihat bahwa Fintech syariah mempunyai landasan maqashid syariah dan juga mempunyai payung hukum yang jelas dan sudah tertuang dalam undangundang. Tinggal bagaimana pemangku kepentingan menjalankan dan mengevaluasi kinerja Fintech syariah yang kedepannya akan memiliki ruang yang signifikan bagi masyarakat muslim Indoneisa. Karena bisa dipahami bahwa regulasi yang dibuat mempunyai titik temu terhadap maqashid syariah, meski regulasi ini belum sempurna dan mencapai titik final, tapi setidaknya sudah baik dan akan dilakukan penegasan dan penambahan regulasi yang akan lebih baik untuk perkembangan Fintech syariah di Indonesia.

\section{Dinamika Fintech Syariah}

Kendala yang dihadapi oleh Fintech syariah yakni mengenai perbedaan akad yang digunakan dalam suatu perusahaan Fintech berbasis syariah, sistem kependudukan ganda yang dimiliki oleh pengguna sehingga menyusahkan pihak Fintech syariah dalam melakukan screening data calon peminjam dana, dan data center yang harus ada di Indonesia. Oleh sebab itu solusinya perlu adanya edukasi teknologi untuk masyarakat, peningkatan jaringan

${ }^{22}$ Shidik. Ushul Fiqh, Jakarta: PT. Intimedia Cipta Nusantara, 2016. 
internet percepatan menuju sistem kependudukan yang terintegrasi sehingga informasi calon peminjam adalah informasi yang valid. ${ }^{23}$ Selain itu kendala yang dihadapi oleh perusahaan Fintech yakni syarat modal yang relatif tinggi ketika hendak mendaftar maka perusahaan yang akan mendaftar harus memiliki dana 1 Milyar dan ketika sudah terdaftar di OJK maka harus memiliki modal 2,5 Milyar. Sehingga hal tersebut menjadi kendala yang terjadi saat ini. Selain itu, jangkauan internet yang masih kurang dalam proses peningkatan kemajuan teknologi dalam bidang Fintech. Serta kurangnya sosialisasi terhadap masyarakat yang ingin menggunakan teknologi Fintech.

Solusi yang harus diwujudkan adalah melakukan edukasi sampai daerah-daerah yang tertinggal sehingga seluruh lapisan masyaraat dapat menikmati kemudahan transaksi Fintech, dan juga membekali masyarakat dengan edukasi Fintech berdasarkan prinsipprinsip syariah. Hal paling prinsip adalah tindakan menghindari dari riba menjadi keunggulan tersendiri bagi setiap individu yang ingin berpindah dari ekonomi konvensional. Sehingga hal tersebut sudah menjadi langkah awal dan upaya untuk menghindarkan diri dari larangan yang Allah sebutkan dalam al-Qur'an yaitu larangan riba. ${ }^{24}$

Perlu adanya pembenahan dalam regulasi hukum karena peraturan yang saat ini dijadikan pedoman oleh Fintech syariah masih mengikutui peraturan Fintech konvensional. Sehingga belum terdapat peraturan khusus yang menjadi legalitas Fintech syariah. Maka oleh sebab itu pihak pembuat regulasi harus membuat peraturan khusus untuk Fintech syariah. Selain itu, dalam upaya mengembangkan Fintech syariah tahap demi tahap sedang dilakukan edukasi studi Fintech kepada seluruh lapisan masyarakat terkait Fintech yang sesuai dengan prinsip-prinsip syariah..$^{25}$

Masalah inti yang dihadapi dalam pengembangan industri teknologi keuangan syariah adalah kurangnya instrumen kebijakan yang menjaga proses kerja Fintech dan ketersediaan sumber daya manusia untuk Fintech. Strategi atau fondasi inti yang diperlukan dalam kerangka pengembangan Fintech syariah adalah kemampuan untuk mengelola dan menganalisa data di era big data dan sumber daya manusia dalam pemasaran digital. Untuk aspek ekosistem atau aktor yang terlibat dalam pengembangan Fintech syariah di Indonesia, aktor pentingnya antara lain pemerintah atau regulator, lembaga pendidikan (universitas), dan juga industri yang ada (bank dan lembaga keuangan lainnya). ${ }^{26}$

\section{PENUTUP}

Dari uraian pembahasan di atas, dapat disimpulkan bahwa Fintech syariah mempunyai landasan maqashid syariah dan juga mempunyai payung hukum yang jelas dan sudah tertuang dalam undang-undang. Dibuktikan bahwa fintech syariah telah memenuhi ke lima maqasyid syariah yaitu menjaga agama, menjaga jiwa, menjaga keturunan, menjaga akal dan menjaga harta serta telah adanya payung hukum berupa perlindungan konsumen yang sudah dimuat dalam POJK No. 77/POJK.01/2016 dan Undang-Undang terkait, yaitu UndangUndang Nomer 8 Tahun 1999 tentang Perlindungan Konsumen (UUPK), Peraturan Pemerintah Nomer 82 Tahun 2012 Tentang Penyelenggara Sistem dan Transaksi Elektronik (PP PSTE), yang merupakan turunan dari Undang-Undang Nomer 11 Tahun 2008 tentang Informasi dan Transaksi Elektronik (UU ITE).

\footnotetext{
23 Dodi Yarli. Analisis Akad Tijarah Pada Transaksi Fintech Syariah Dengan Pendekatan Maqashid. Jurnal Pemikiran Hukum dan Hukum Islam Vol. 9 No. 2. Desember 2018.

24 Ibid.

25 Ibid.

26 Aam Slamet Rusydiana. Bagaimana Mengembangkan Industri Fintech Syariah di Indonesia? Pendekatan Interpreative Structural Model (ISM). Jurnal Al-Muzara'ah Vol. 6 N0. 2, 2018.
} 


\section{DAFTAR PUSTAKA}

Aam Slamet Rusydiana. 2018. Bagaimana Mengembangkan Industri Fintech Syariah di Indonesia? Pendekatan Interpreative Structural Model (ISM). Jurnal Al-Muzara'ah Vol. 6 N0. 2.

Achmad Basori Alwi, 2018. Pembiayaan Berbasis Teknologi Informasi (Fintech) yang berdasarkan Syariah. Jurnal Al- Qonun, Vol. 21, No.2.

Arifiyah, Ismiyatul. 2018. Perlindungan Hukum Terhadap Pengguna Pada Transaksi Bisnis Teknologi Finansial Berdasarkan Prinsip Syariah. Jakarta: Skripsi Fakultas Ekonomi dan Bisnis, UIN Syarif Hidayatullah.

Arner, D. W. 2016. Opportunities and Challenges. Fintech and RegTech.

Chuen, D.L.K., \& Teo, G.S. 2015. Emergence of fintech and the LASIC principles. The Journal of Financial Perspectives: Fintech, Winter 2015.

CIBAFI. 2018. 'Evaluating future impacts: Strategic thinking, branding, and financial technologies'. Global Islamic Bankers' Survey 2018.

Dewi Sartika Nasution. 2017. Urgensi Fintech Dalam Kurikulum Pendidikan Tinggi. Iqtishaduna Jurnal Ekonomi Syariah Vol. 8 No.2.

Dodi Yarli, 2018. Analisis Akad Tijarah Pada Transaksi Fintech Syariah Dengan Pendekatan Maqashid. Jurnal Pemikiran Hukum dan Hukum Islam, Vol. 9, No. 2.

Fadlan, Fadlan. "KONSEP PEMBANGUNAN EKONOMI BERBASIS ISLAM (Sebuah Upaya Pembangunan Ekonomi Indonesia yang Adil, Makmur, dan Sejahtera)." Al-Ihkam: Jurnal Hukum \& Pranata Sosial 5, no. 2 (2012): 257-274.

Farizal. 2010. Pengembangan Kompetensi SDM Perbankan Syari'ah Melalui Corporate University, Forum Riset Perbankan Syariah II. Yogyakarta. Universitas Muhammadiyah Yogyakarta.

Fauzia, Ika Yunia, dan Abdul Kadir Riyadi, 2018. Prinsip Dasar Ekonomi Islam Perspektif Maqashid al- Syariah. Jakarta: Prenada media Group.

Fintek, PT Amartha Mikro. 2017. Dipetik Oktober 1, 2018, dari https://amartha.com

Firdaus, Muhammad Irkham, 2018. Layanan Keuangan Digital Perspektif Hukum Keuangan Islam. Tesis. UIN sunan Kalijaga Yogyakarta.

Hadad, M.D. 2017. Financial Technology (Fintech) di Indonesia. Kuliah Umum tentang Fintech, Indonesia Banking School.

Harrison, R., Jaumandreu, J., Mairesse, J., \& Peters, B. 2014. Does innovation stimulate employement? A firm level analysis using comparable micro-data from four European countries. International Journal of Industrial Organization.

Hasan, S.M. 2018. Fintech in Indonesia: An Islamic outlook", article in http://ethiscrowd.com.

Hasan. 1970. The Early Development of Islamic Jurisprudence. Islamabad: Islamic Research Institute.

https://www.ojk.go.id/id/berita-dan-kegiatan/publikasi/Pages/Penyelenggara-FintechTerdaftar dan-Berizin-di-OJK-per-31-Mei-2019.aspx

Kasali, R. 2017. Discruption. Jakarta: Gramedia Pustaka Utama. 